\title{
ECOLOGICAL RISK ASSESSMENT MODEL FOR THE „JADAR” PROJECT
}

\author{
Saša Bakrač ${ }^{1,2 *}$ \\ ${ }^{1}$ Military Geographical Institute, \\ Belgrade, Serbia \\ ${ }^{2}$ Military Academy, University of Defence, \\ Belgrade, Serbia
}

\begin{abstract}
:
This paper presents a general framework for environmental risk assessment for the project "Jadar" - exploitation and processing of minerals "Jadarit". Conceptually, the paper is set up to provide insight into the applicability of a given model of environmental risk assessment.

This model is based on a scientific and proven methodology. The paper emphasizes the complexity of assessment and the need for a broad scientific approach. This environmental risk assessment is based on three potential sources of risk: mining activities, production-industrial activities and the generation of industrial waste.

As a possibility of negative impacts on the territory of the "Jadar" project, it is assumed that ecosystems, habitats and the environment would suffer consequences in general. The paper is expected to stimulate discussion and offer a proposal for solving this issue - the problem.
\end{abstract}

Keywords:

Environment, Assessment Phases, Stressor, Key points, Conceptual Model.
Correspondence:

Saša Bakrač

e-mail:

bakrac2017@gmail.com

\section{INTRODUCTION}

The subject of this paper is the proposal of the model of environmental risk assessment, as a consequence of the realization of the project "Jadar" (hereinafter the Project).

The subject of the paper is spatially determined by the territory of the Project realization. The timing of the subject of the work includes the planned period from the beginning to the end of the Project implementation (at least 50 years). The Project envisages the construction of an underground mine, with two shafts with a diameter of about eight meters, which descend to a depth of 650 meters. The production of lithium carbonate, boric acid and sodium sulfate is planned within the Project. Lithium carbonate can be easily converted to lithium hydroxide and lithium phosphate from which batteries for electric vehicles are made [1]. 
The project is expected to generate revenues for the Republic of Serbia of around 30 million per year or 300 million euros for a decade.

The aim of this paper is to assess the environmental risk as a consequence of the future realization of the Project on a scientifically based approach. The paper presents a model of the environmental risk assessment, based on a methodology that has been tested and scientifically proven. Identifying and describing sources of pollution, stressors, analyzing future effects of pollution and assessing environmental risks are requires an interdisciplinary scientific approach.

Taking into account the current state of the environment, with the growing impact of climate change, the implementation of the Project is an activity that has the potential for further deterioration of the ecological condition.

Applying the given model of ecological risk assessment would give precise answers about the potential of ecological risks in the observed area.

\section{TYPES SPATIAL DETERMINATION OF THE PROJECT OF CONTENT}

The Project area covers an area of $293.91 \mathrm{~km} 2$ and on the territory of local self-government units: - the city of Loznica - entire cadastral municipalities (CM): Runjani, Lipnica, Bradić, Brnjac, Veliko Selo, Jarebice, Draginac, Simino Brdo, Cikote, Šurice, Stupnica, Slatina, Korenita, Gornje Nedeljice, Donje Nedeljice, Grnčara and Šor; municipality of Krupanj - entire cadastral municipalities (CM): Kostajnik, Dvorska, Brezovice, Krasava and Cerova [1].

\begin{tabular}{ccc}
\hline $\begin{array}{c}\text { Local self- } \\
\text { government unit }\end{array}$ & $\begin{array}{c}\text { Area of the covered } \\
\text { part of the territory } \\
\text { of the local self- } \\
\text { government }\left(\mathrm{km}^{2}\right)\end{array}$ & $\%$ \\
\hline City of Loznica & 194,81 & 66,28 \\
\hline $\begin{array}{c}\text { Municipality of } \\
\text { Krupanj }\end{array}$ & 99,10 & 33,72 \\
\hline Total & 293,91 & 100 \\
\hline
\end{tabular}

Table 1: Scope and area of the Spatial Plan area (Source: Institute of Architecture and Urbanism of Serbia)
The spatial scope of the Project is determined by the borders of entire cadastral municipalities and is graphically shown in Figure 1. The border represents a special purpose area in a broader sense [1].

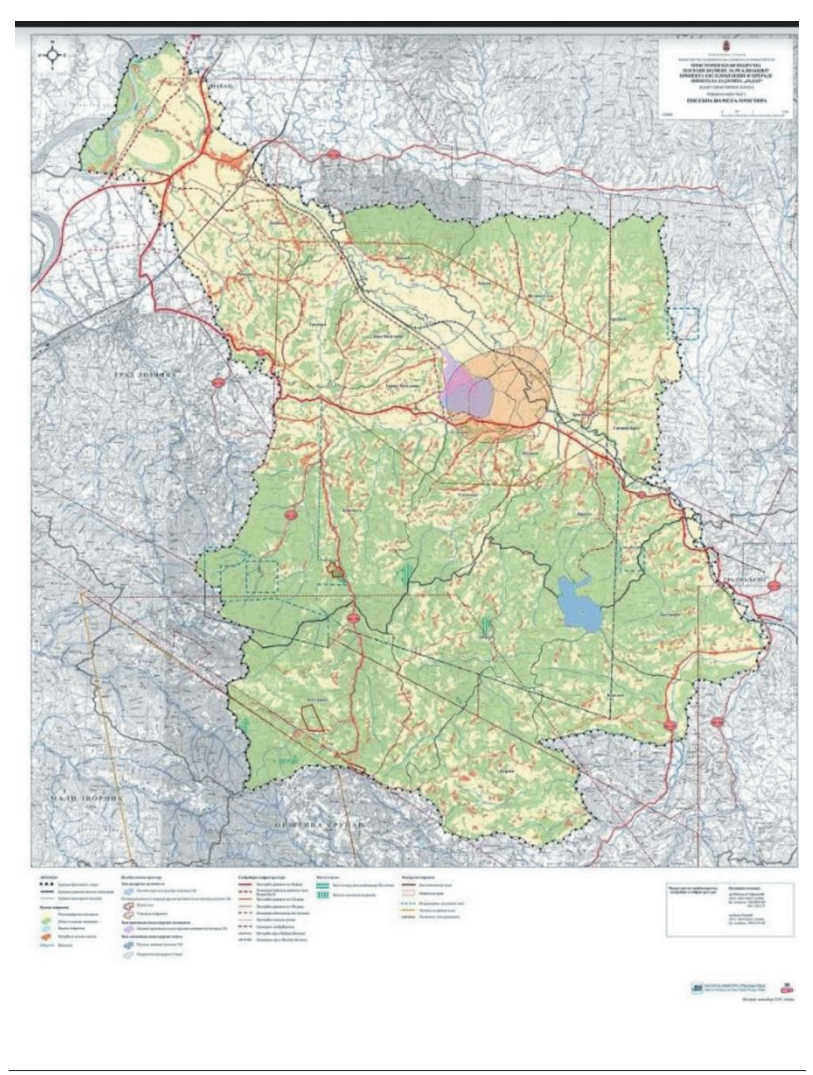

Figure 1 - The map of the Project area in the scale of R 1:25.000 (Source: http//mgsi.gov.rs. [2]).

\section{ECOLOGICAL RISK ASSESSMENT MODEL}

It is assumed that the implementation of the Project there is an environmental risk of excessive pollution. This can cause environmental problems and consequences for the environment of this and wider area.

This pollution is determined by time. It can be considered from the beginning, during and after the realization of the Project.

In order to successfully address these dilemmas, it is necessary to use an adequate methodology based on science [3]. The assessment in question would use an environmental risk assessment model developed by the US Environmental Protection Agency [4]. The applied methodology of environmental risk assessment, which is internationally validated both in theoretical and practical terms, provides a good basis for its implementation in this case as well. 
In that sense, the application of the given methodology of ecological risk assessment would determine the current ecological condition and the present risks with the aim of reducing them in the future. In general, environmental risk assessment can be defined in a way that it is a process of: collecting, organizing, analyzing and presenting scientific data in order to make decisions that provide protection and improvement of the ecological condition of the observed area [5]. Defined in this way, environmental risk assessment is a unique form of assessment that includes the term risk and which assumes a cause-and-effect relationship (relationship) stressor response. The term ecological risk means the function of the probability of a given source of threat - stressor, which uses a certain potential sensitivity of an ecological system, and the corresponding response of the same to a given event. The term stressor refers to any physical, chemical or biological entity that can induce a negative reaction [6].

Environmental risk assessment of the Project implementation is a process that would be carried out in stages as follows:

- Assessment planning

- Problem formulation

- establishing clear management goals and guidelines

- determination of stressors

- selection and definition of key assessment points

- development of a conceptual model

- development of an analysis plan

- Implementation of the Risk Analysis phase

- evaluation of data and models for Analysis

- characterization of exposure and environmental effects

- Implementation of the risk characterization phase

- risk assessment

- risk description

- linking the obtained information with management decisions

Having in mind the complexity and scope of the model, this paper provides a general overview, with an emphasis on defining the stages of assessment and development the conceptual model. The conceptual model is one of the most important elements of the overall process and provides the basis for the whole assessment.

\subsection{ASSESSMENT PLANNING}

Environmental risk assessment planning must be separate from the scientific part of the assessment. [4] In this particular case, this would include:

- formation of a working group (team) for assessment,

- clearly defined goals and tasks of the management,

- defined management options in the context of achieving the set goals and

- agreement on the scope, complexity and focus of the risk assessment including the expected result and the technical and financial assistance needed to achieve the set goals.

One of the most important planning products would be to establish management goals and objectives. In this case, the main goal could be: Determining the quality of the environment during and after the implementation of the Project.

Some of the management objectives of a given assessment, which more explicitly explain possible objectives and which are grouped together in the main objective, could be:

- Determining the current state of the environment, including current quantities for individual pollutants

- Determining the state of quality of environmental elements (water, air, soil)

- Determining the state of health of plants, animals and other organisms, excluding humans.

- Establishment/implementation of measures to improve the state of the environment.

\subsection{PROBLEM FORMULATION}

Preliminary hypotheses are made here about what environmental effects have occurred or may occur in a given procedure [6]. This phase provides the basis for a complete environmental risk assessment of the consequences of the Project implementation.

From the collected (available) information, the following products would be prepared: defined stressors and key assessment points; conceptual model (s) developed, risk hypotheses defined and risk analysis plan defined.

Stressors should be ranked according to the potential risk for all living space resources of the Project implementation and beyond. 
This would be done on the basis of professional assessment by the working group. The results of the comparative analysis could first rank the pollutants, in order to verify the assumption that they are the biggest stressors for the environment of the subject area. It would be necessary to examine each stressor separately, in order to study the intensity of their impact on the environment and to determine their current state and possible increase during the implementation of the Project.

Potential stressors could be:

- physical pollutants,

- chemical pollutants,

- pollutants in the air,

- pollutants in the soil,

- pollutants in water.

The key points of the assessment are an expression of the current values of the environment we want to preserve [6]. The key points of this assessment should be: environmentally relevant, that they are related to existing stressors and that they are related to previously adopted management objectives [4].

Potential key assessment points could be:

- health of plants, animals and other organisms,

- contamination of the space,

- \% representations of diseases of organisms,

- distribution and number of organisms,

- quality of groundwater and running water and soil and

- food quality in the food chain.

According to the definition, "conceptual models are mathematical models that are composed of a small number of simple elements, and each element simulates a specific phase of the process" [5]. The conceptual model in the present case would belong to the group of complex models and could be given in the form of diagrams (Figure 2). This presentation provides a description and visual presentation of the predicted relationships between environmental entities (selected key assessment points) and the stressors to which they may be exposed. All pathways in the diagram are also risk hypotheses, because they concern certain information related to this assessment. The complexity of this conceptual model-data diagram is conditioned by the complexity of the problem: the number of stressors, the number of key points, the nature of the effects and the characteristics of the ecosystem. In the case of this assessment, it can be argued with certainty that the conceptual model would be very complex.
Risk hypotheses are proposed answers to risk assessor questions about what key point reactions will show when exposed to stressors and how that exposure will occur. Risk hypotheses are specific assumptions about the potential risk of key points. In the conceptual model, risk hypotheses represent connections and can also be used to ask questions important for research in order to assess the logical and empirical consequences, in order to create a basis for risk assessment.

Regarding the establishment of risk hypotheses, in this case they could be initiated: protection of ecological values, the impact of stressors on organisms or caused ecological effects (disease of organisms, pollution and loss of habitats, etc.). Thus, some of the hypotheses could be: that excessive pollution of the elements of the environment causes a decrease in the number of organisms.

To define and develop an analysis plan, it would be necessary to once again consider the set the risk hypotheses in order to determine the method of assessment, using available and newly arrived data. It would be the obligation of the working group to make a comparative, ie. comparative risk analysis, to help define which stressors and key assessment points should be examined.

\subsection{IMPLEMENTATION PHASE OF THE RISK ANALYSIS}

Risk analysis is a strategic phase in environmental risk assessment [6]. In a given case, this phase would be the most extensive and demanding of all assessment phases, both in quantitative and qualitative terms. The analysis would examine the two basic components of risk, exposure and effects, and their interrelationship [5]. Before proceeding with the realization of exposure characterization and characterization of ecological effects, it would be necessary to evaluate the available data and the defined analysis model. This model would include an assessment of possible uncertainties that accompany this phase. This would include an assessment of the possibilities and limitations of the different data types, an assessment of the modeling study, as well as an assessment of the overall uncertainty regarding the quality of the data and the set model.

After conducting assessments on available data and the projected modeling study, as well as possible uncertainties and shortcomings in the assessment process so far, the characterization of exposure and the characterization of effects would be approached as the next phases of the analysis. 


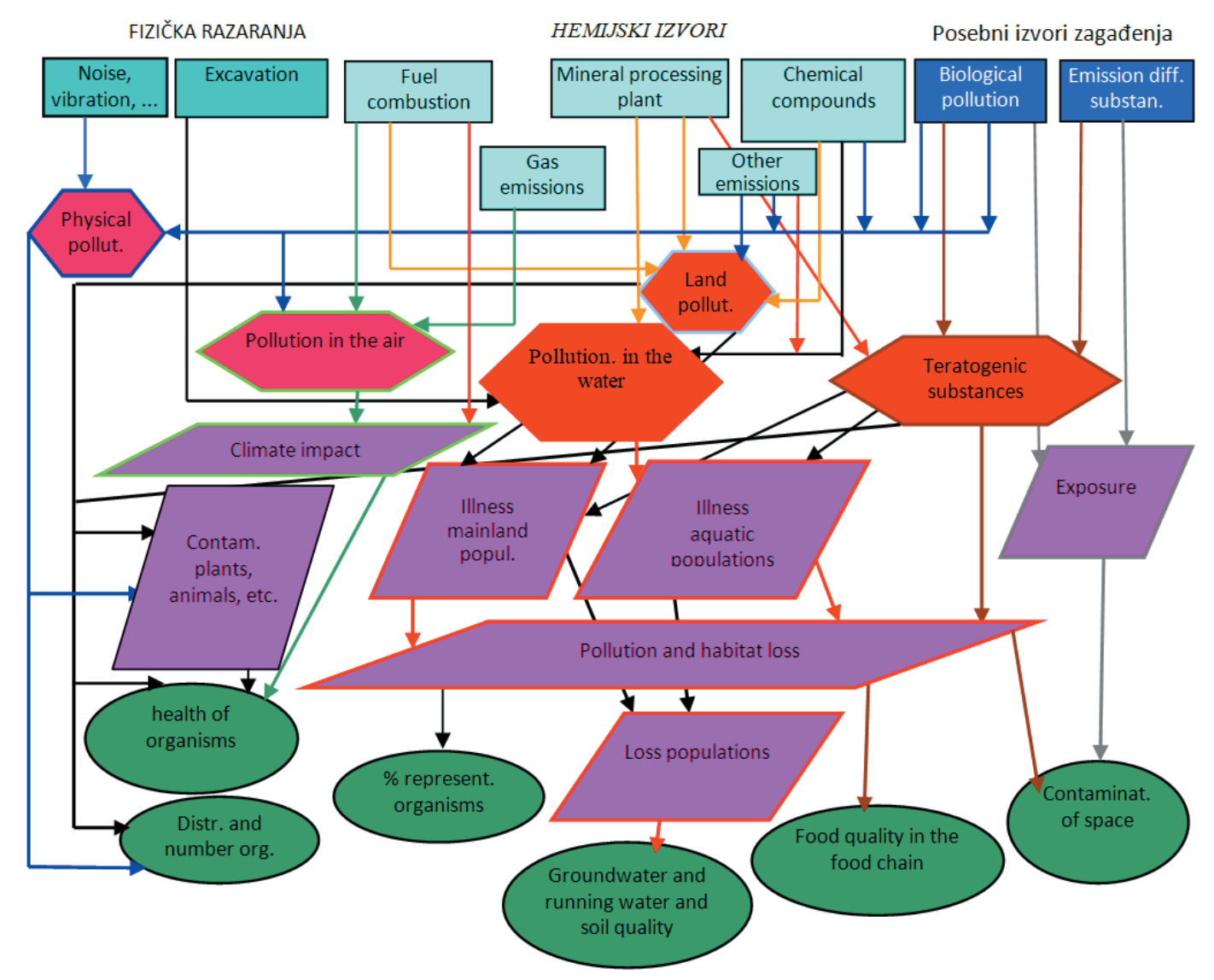

Figure 2 - Conceptual model diagram

Exposure characterization would rely on the set model of analysis. Depending on the type (character) of the assessment, adequate models are also applied (models that are universal or special models are made) [4]. In this assessment, the process would be based on exposure analysis and a description of the degree and pattern of contact or the simultaneous occurrence of defined stressors and receptors. The final product of this phase would be the so-called exposure profile [3].

Characterization of ecological effects as the next phase of analysis would include the work of an assessor who analyzes-describes the effects of the environmental response and links them to selected key assessment points. In general, characterization would begin with an assessment of data on the effects caused by a given stressor / stressors, and would continue with an analysis of the ecological response, which would assess how the extent of the effects changes with varying levels of the stressors. By this procedure, the evaluator (s) would prove that the stressors caused a certain effect, which connects the effects with the key points of the assessment and the defined the conceptual model. The conclusions would be summarized in a stressor-response profile [6].

\subsection{IMPLEMENTATION OF THE RISK CHARACTERIZATION PHASE}

The final phase of environmental risk assessment is risk characterization. It represents the culmination of planning, problem formulation, and analysis of predicted and observed adverse environmental effects related to defined key points [4].

The aim of the risk assessor in this case would be to gain full insight into the relationships between defined stressors, effects and key assessment points and to draw conclusions regarding exposure and damage caused by existing or projected environmental effects (environmental risk). The results of the analysis phase would be used by the assessors to develop a risk assessment of the ecological entities, primarily including the key points identified in the problem formulation. A risk description would also be given in the context of the importance of any adverse effect, as well as evidence supporting its likelihood. Finally, it would be the responsibility of the assessor to identify and summarize the uncertainties and assumptions in the risk assessment, and to report to the risk managers on the conclusions of the assessment. 
The conclusions presented in the characterization of the risks from the consequences of the Project implementation should provide clear information to the risk managers in order to make the right decision related to the given problem. If the risks are not sufficiently defined and clear to make a management decision, then risk managers may decide to repeat one or more phases of the assessment. Reassessing the conceptual model (and related risk hypotheses) or conducting additional studies may improve risk assessment [6].

\section{CONCLUSION}

The application of the given methodology of environmental risk assessment would respond in clarifying the potential risks caused by the implementation of the Project. The methodology is clear and validated on many other similar examples, but its success and validation require both consistent application and good knowledge.

Therefore, in this case it would be necessary to apply environmental risk assessment using the established methodology with previously well prepared preparation of the selected management, with a quality selection of experts - assessors and with the adequate economic support of the client.

It is believed that an environmental risk assessment conducted in this way would be the initiator of solving many non-environmental problems that are present in the narrower and wider larger urban and industrial areas. This primarily refers to the development of economic (tourist, agricultural, economic), political and other potentials, but also to the development of society's attitude towards environmental protection. The obtained evaluation results would also be valuable data for monitoring and improving the situation, but also a good basis for further research and re-evaluation.

Given the complexity of the subject matter, and in order to better understand the research problem, this paper gives only a general approach, so that the chapters that make up the structure of the work (assessment methodologies) are treated in abbreviated form. The concretization of the paper would be checked and applied on a much broader theoretical-methodological basis.

\section{REFERENCES}

[1] Institute of Architecture and Urbanism of Serbia, "Prostorni plan područja posebne namene za realizaciju projekta eksploatacije i prerade minerala jadarita „Jadar“, Beograd, Serbia, 2019.

[2] http//mgsi.gov.rs.

[3] S. Bakrač, "Development of environmental risk assessment and management methodology on the example of the Bokakotorska Bay", doctoral thesis, University of Belgrade, Faculty of Geography, Belgrade, 2008.

[4] U.S. EPA, "Guidelines for ecological risk assessment", Washington, DC: EPA/630/R-95/002Fa, 1998.

[5] S. Bakrač, M. Vuruna, M. Milanović, "Procena ekološkog rizika u funkciji zaštite životne sredine”. Military Technical Bulletin, number 4, year LX, october-december, pp. 165-178, 2012

[6] GW. Suter, "Ecological risk assessment", Second Edition. USA: CRC Pres, 2006. 